\title{
Feelings of Loneliness: Understanding the Risk of Suicidal Ideation in Adolescents with Internet Addiction
}

\author{
Eugénie Khatcherian ${ }^{1}$, Daniele Zullino', Diego De Leo ${ }^{2,3,4}$ and Sophia Achab ${ }^{1 *}$
}

1 Addiction Division, Department of Mental Health and Psychiatry, Hospital and University of Geneva, Geneva, Switzerland

2 Department of Psychology, Primorska University, Slovenia; ${ }^{3}$ AISRAP, Griffith University, Australia; ${ }^{4}$ De Leo Fund, Italy

* Correspondence: sophia.achab@hcuge.ch.

\begin{abstract}
The Internet has become an essential tool for adolescents. It is part of their social integration within peers and supports their identity construction. The Internet can also become a source of addiction; especially when used as a coping strategy towards unpleasant life situations. The feeling of loneliness is an emotion present during the adolescence. However, when in excess, it can lead to suicidal ideations. We questioned ourselves on the impact of an excessive use of the Internet by adolescents, with their feeling of loneliness and the risks of suicidal ideations. We attempted to find an answer to this question by performing a literature review. We found one result matching our search criteria's, which is itself a literature review. We noted the absence of studies with regards to the interaction between the feeling of loneliness, the addiction to the Internet, and the risk of suicidal ideations amongst adolescents. We established a theoretical model which could be used as a lead for future research. We insist on the importance that studies are made in this domain, in order to enable us to establish efficient preventive measure on the risks of suicidal ideations amongst adolescents.
\end{abstract}

Keywords: suicidal ideation; adolescent; internet addiction; loneliness

\section{Introduction}

\subsection{Identity construction at the adolescence}

The adolescence is marked by the passage from childhood to adulthood. The adolescent is confronted to a body in transformation as well as to the emergence of sexuality. He must appropriate his new body, face new impulses, all while developing his identity as an adult in the making. These processes can only happen by distancing himself from the parenthood images, enabling the adolescent to construct a different identity from his parent's. The adolescent weakened by his constructing self-reflection will seek landmarks and the support from peers. The adolescent is marked by the need to belong to a group of peers offering identification models on which relying on to build his identity, all while developing his singularity [1].

\subsection{Usage of the Internet by the adolescent and addiction to it}

The adolescents are the part of the population which uses the Internet the most. The Internet offers a vast diversity of occupations and experiences. It has become an information, learning support, discovery, communication and entertainment tool [2].

The Internet constitutes for adolescents a space to extend their identity construction. As a matter of fact, it is a space where they can gather outside of the parental oversight, shape to their norms, with a common shared language and preferences. Within this space, the adolescent may find the feeling of belongingness to a group and identification figures. The Internet will also offer the opportunity for the adolescent to create virtual identities. 
Avatars which they shape towards the image they wish to show. This virtual construction is part of the process of identity construction of the adolescent. Enabling him to experiment whatever he wishes to be, and whoever he can be within his peers $[1,3]$.

For adolescent in industrialized countries, the Internet has become an essential tool in their identity development and socialization.

However, the use of the Internet can also have negative consequences. Particularly the development of an addiction. A meta-analysis from 2014 that reviewed studies from 31 nations reported that the global occurrence of Internet addiction was estimated at $6 \%$ [4]. Adolescents are the part of the population with the highest risks of presenting an addiction to the Internet $[5,6]$. The prevalence of Internet addictions varies from one region to another. In Europe, the prevalence varies between 1,2\% and 11,8\%. In China, the prevalence varies between $9,56 \%$ and $24 \%$. We find a $20,6 \%$ prevalence in the USA, and $18 \%$ in Canada. In South Korea, it reaches $30 \%$ of adolescents being at risk of Internet and smartphone addictions and in Japan, 23,7\% of adolescents are classified as Internet addicts [7]. The vast differences between the prevalence's are explained by the difference in the criteria used in the diagnosis. As well as the difference in age and culture of the studied group of population [6]. Internet addiction is often associated with comorbid psychosocial issues (i.e. self-isolating, depressive mood, suicidal behaviors, anxiety disorders, poor academic performance) and other health issues (i.e. vision, sleep, sedentarity, muskulosqueletal disorders) [6].

The concept of Internet addiction covers a very heterogeneous set of problematic behaviours. As a number of devices can be used, (computers, smartphone, tablets, gaming consoles, etc.) with extremely variable and fluctuating usage (social medias, video games, sexual content, video viewing, information retrieval ...)[6]. Internet is the vector of potential addictive patterns of use of some online activities such as gaming and gambling, these two disorders have recently been recognized by WHO in ICD-11 draft as addictive behaviours [8][1].

Despite these vast variations in the prevalence and behaviours, the addiction to the Internet is a real public health issue. As concluded in the WHO meeting of August 2014 on the topic of the impact on public health of excessive us of internet, computers, smartphones, and similar electronic devices. This meeting performed a review of available evidence and established the main direction of future research to be made. Experts have concluded that given the extent of the negative repercussions on health, the high rates of comorbid psychiatric disorders including suicidal behaviours, effective prevention policies are needed [6].

Multiple elements being able to lead the adolescent towards an Internet addition have already been identified in the literature.

The first one, is seeking online to compensate a negative life situation and associated emotions. The Internet can then play one or more of several roles [3] [9]:

- It can be a mean to escape from reality, to flee a negative situation and emotions. This behaviour is described in the literature as escapism;

- It can be a mean to find online what he cannot find in the real life ;

- It can be a mean to replay online difficulties encountered in the real life, in order to find means to overcome them;

- It can be a place of sublimation for negative emotions.

The second element is the usage of the Internet by adolescent with a greater impulsive drive, in a constant quest for novelty and short term reward [10,11,12]. Within that group of adolescents are most notably found those suffering from ADHD. 


\subsection{Loneliness at the adolescence}

Loneliness is a subjective mental state of an individual with a significant deficit in his relationship to others. This deficit can be quantitative or qualitative. It is relative, emerging from the comparison made by the subject towards the social norms, the ideal sociability he aspires to, as well as the one from his entourage $[13,14]$.

It is crucial to differentiate loneliness and social isolation. Social isolation is an objective state and designs a quantifiable lack of social proximity and engagement with others. A socially isolated individual may not feel loneliness. Conversely, an individual with a lot of social interactions may have a feeling of loneliness [13,14].

The adolescence is a period in life that is frequently marked by feelings of loneliness $[14,15]$. The adolescent feels the void left by the parenthood identification models. This confrontation with loneliness enables the adolescent to gain autonomy, to think by himself, make his own decisions and affirm himself as an individual [14].

The adolescent is in a twofold movement. On one hand, he seeks to isolate himself, while simultaneously seeking the company of his peers to fulfil his needs for attachment and belonging. Friends will allow to share emotions, the ongoing transformations upheavals. However, the quest for a group of peers to integrate with can be a tedious one. It requires to find peers with whom the adolescent will find similitudes, share affinities and create trust ties. If the adolescent fails to find a group of peers, this will be accompanied by an exacerbated feeling of strangeness and loneliness [1, 14].

\subsection{Suicidal Ideation and dying by suicide in adolescence}

Suicide is an important public health issue, especially in adolescents. Suicide is the second cause of death for individuals aged from 15 to 29 years old in the world [16]. As observed, adolescence is a period of mental fragility. The feeling of loneliness lived during the adolescence can, if exacerbated, lead to suicidal ideation or even acts of suicide. Loneliness is an important risk factor in the building up of suicidal ideation or in suicide occurrences [17, 15]. The Interpersonal Theory of Suicide by Thomas E. Joiner (2005) points specifically to the lack of feelings of belongingness as one of the main risk factors in the construction of suicidal ideation [18]. In this theory, Thwarted Belongingness and Perceived Burdensomeness (the perception of being a burden on others) are the two factors that would lead to active suicidal ideation $[18,19]$.

A study performed in 23 European countries went even further, by demonstrating that individuals who were living within communities based on mutual aid, registered less suicides. As member of these communities, the individual perceives himself as being part of the group and useful to others. As others rely on him, and he relies on others to solve problematic situations which arise [20]. These elements converge with the observation in the literature of the reduction in the risk of suicide among adolescents who benefit from social support from their family and friend [21, 22]. We can infer that the adolescent, part of a family structure and a group of friends based on trust and mutual aid, will feel a sense of belongingness and a weak sense of burdensomeness.

\subsection{Research question}

What is the impact of the use of the Internet on adolescents' feelings of loneliness and the subsequent risk of developing suicidal ideation? The question can be particularly relevant when considering adolescents with an excessive use of the Internet. Is an excessive usage going to affect feelings of belongingness and feed loneliness? Will it exacerbate one or the other? What would be its impact on the development of suicidal ideation?

To try answering these questions, we performed a literature review. 


\section{Materials and Methods}

Initially, we used the following three online databases to perform our literature searches:

- Scopus

- Pubmed

- $\quad$ PsycINFO

The searches were performed on the 10th of January 2020 with the following keywords: adolescent AND loneliness AND ("suicidal ideation" OR suicide) AND ("problematic use of internet" OR "excessive use of internet" OR "internet addiction"). On Scopus, we limited our search to literature reviews as well as research articles.

The result of our searches on the different online databases were:

- 61 hits on Scopus

- 0 hit on Pubmed

- 1 hit on PsycInfo

We did a pre-selection based on the titles and abstracts of the search results. Fourteen articles were found to be relevant. The final selection was made by reviewing the full text of each article. Only one article was found to be relevant.

Keyword search:

Adolescent AND loneliness AND ("suicidal ideation" OR suicide) AND ("problematic use of internet" OR "excessive use of internet" OR "internet addiction")

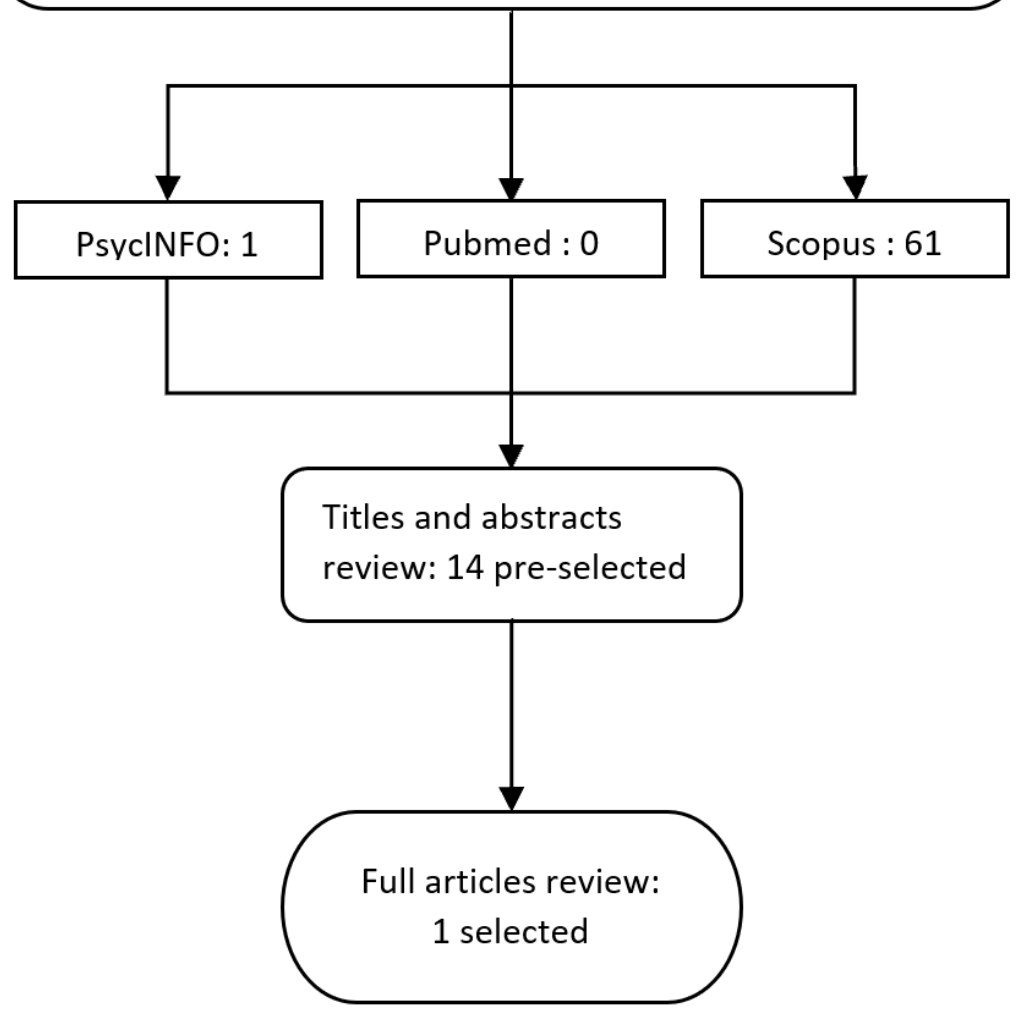

Figure 1: Initial search, performed on the 10th of January 2020. 
Given the results mentioned above, we decided to perform another search on the three online databases by using a small variation of the keywords used. The word "adolescent" was replaced by the word "teenager".

The searches were performed on the 11th of June 2020 with the following keywords: Teenager AND loneliness AND ("suicidal ideation" OR suicide) AND ("problematic use of internet" OR "excessive use of internet" OR "internet addiction")

On Scopus, we limited our search to literature reviews, as well as research articles. The result of our searches on the different online databases were:

- 19 hits on Scopus

- 0 hit on Pubmed

- $\quad 0$ hit on PsycInfo

We used the same approach for the pre-selection: review of the titles and abstract. In addition, we removed duplicates from the first results. Two articles were found to be relevant.

Finally, we performed a full review of the pre-selected articles. None were found to be specifically relevant.

Keyword search:

Teenager AND loneliness AND ("suicidal ideation" OR suicide) AND ("problematic use of internet" OR "excessive use of internet" OR "internet addiction")

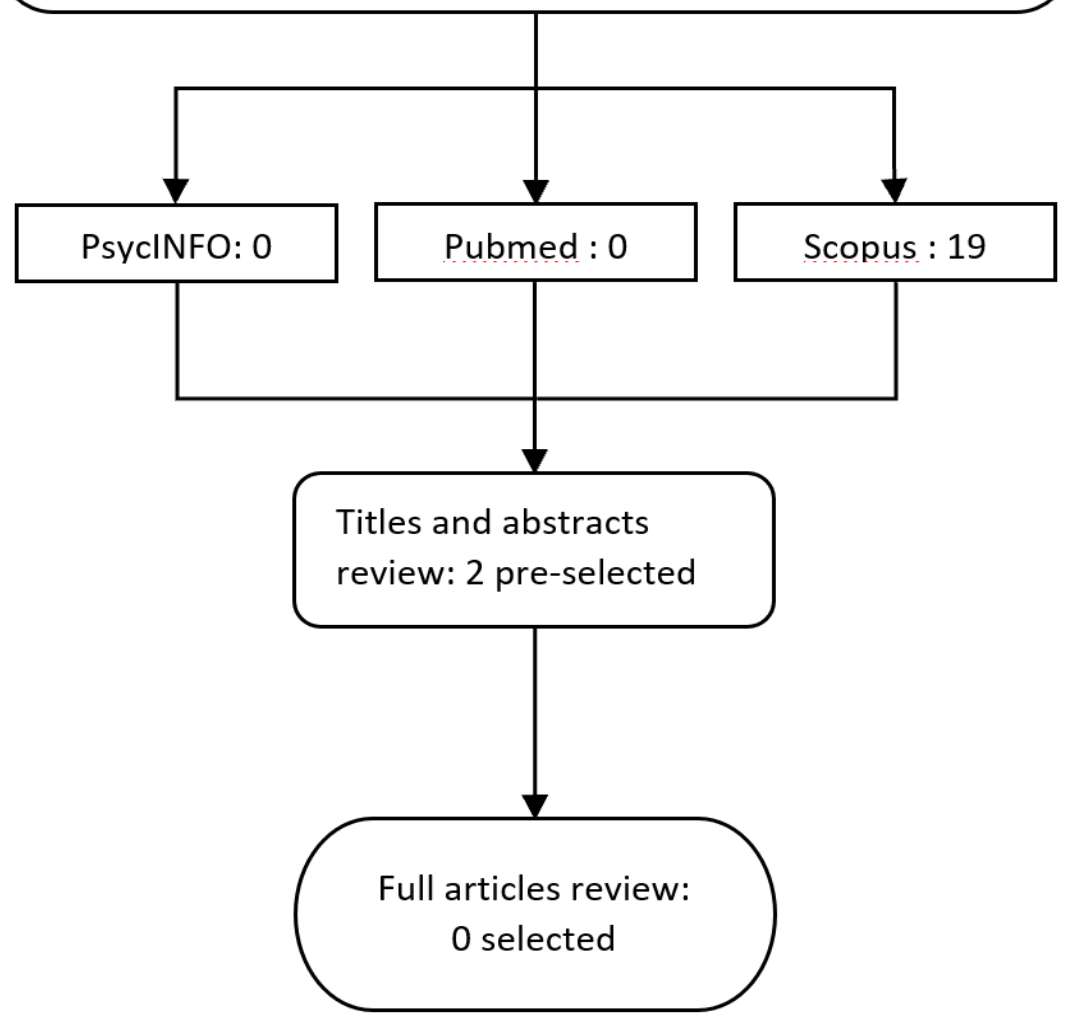

Figure 2: Second search, performed on the 11th of June 2020 


\section{Results}

The article "Relationship between adolescent suicidality, self-injury and media habits" from Erin L. Belfort and Lindsay Miller was the only one which matched our research criteria [23]. This article is a case report, followed by a literature review.

\subsection{The Internet and the feeling of loneliness}

The article mentions the use of social media as a tool for identifying construction during adolescence. Belfort and Miller mention the hypothesis of some researchers-that the adolescent casted aside or socially anxious would benefit from online platforms to create their social network. However, they also mention the finding of some research which reveal that adolescent with communication skills would increase the social capital and enrich their social life via social networks, while the ones with little communication capabilities would not be able to increase their social capital. Furthermore, the later would be confronted by more pervasive feelings of loneliness.

The article underlines that adolescents which belongs to a social minority, defined by a peculiarity distinguishing them (such as the sexual orientation, a mental illness, etc.) would be able to find communities within which to share their experiences and difficulties, without being stigmatised. Thereby, in these situations, social networks enable the usually-excluded adolescents to find enriching social ties [23].

The article mentions the importance of the type of platform used. The content to which the adolescent will be exposed, as well as the specific impact it can have on a given individual. Adolescents can use social networks in an active or passive manner.

In the active usage, the adolescent is actively interacting with others on social networks. Whereas in the passive usage, the adolescent is simply scrutinizing the social networks without interacting with other people. Active usage is often linked with a decrease in feelings of loneliness, while passive use generally produces an increase in feelings of loneliness. Among passive users, there are cases of adolescents that are scrutinizing social networks in an obsessive manner, with the fear of missing important events. This phenomenon is described as FOMO (Fear of Missing Out) and is considered as a form of severe anxiety for being excluded [23].

\subsection{The Internet and suicidal thoughts}

Studies show that over $90 \%$ of the adolescents suffering from a mental illness will seek help on the Internet. They perceive an ease of accessing this mean and the possibility to remain anonymous. Adolescents in difficulty will find it easier to seek help online or express their emotions on social networks rather than asking the help of an adult.

The literature is highlighting an indirect and complex association of the use of the Internet and the suicidal behaviour of adolescents. Belfort and Miller's article specifies the importance of considering the content of the information posted and seen by each adolescent and to relate it to his or her singularities. The article also mentions the contagion phenomenon or incitation to suicidal behaviours on the Internet. Adolescents are extremely sensitive to contagion phenomenon. The literature noted that the exposition to suicidal behaviours amongst the inner circle of the adolescent or via the media increased the risks of suicidal behaviour for adolescents. However, Belfort and Miller specify that one study differentiated the exposure to the announcement of a suicide on a social media or on an online forum. The exposition to the announcement of a suicide on a social media is not linked to an increase of suicidal ideation, whereas the exposition of such an announcement on an online forum is. Belfort and Miller mention the hypothesis from the literature that the degree of "connectedness", or at the very least, the "perceived connectedness" is a crucial element to the comprehension of the impact of the information the adolescent is exposed to [23]. 


\section{Discussion}

\subsection{Insufficient literature}

The small number of articles dealing with the links between feelings of loneliness, excessive usage of the Internet, and suicidal ideation was somewhat surprising. Several reasons can explain this absence in the literature: our first hypothesis is that the addiction to the Internet is a recent concept, which is still controversial amongst the scientific community [6]. Furthermore, we noticed the concept is still unrecognised and vague for a vast number of healthcare professionals. The distinction between a passionate or pathological behaviour is still under discussion by experts [24].

\subsection{Knowledge from the literature}

\subsubsection{Internet investment by adolescents with feelings of loneliness}

The article by Belfort and Miller puts forward the existing complexity between feelings of loneliness, misuse of the Internet and presence of suicidal ideation [23].

The authors mention the hypothesis where adolescents suffering from relational difficulties will make use of the Internet to compensate their deficits in social capital [23]. This hypothesis is confirmed by an article that identifies an increase in problematic use of Facebook by adolescents suffering from social anxiety and in need of social reassuring [25]. Furthermore, an article by Xiao-Shuang et al. mentions the use of the Internet as a means to fill the lack of social support by some adolescents [26]. Others articles also identify the lack of self-esteem as a fostering element in the development of addiction to the Internet [27, 28]. Lack of self-esteem seems to be an element paired by the need of social reassuring, as well as by frequent feelings of loneliness [29].

Some articles go further by bringing forward the fact that the Internet can be used by adolescents as a coping strategy to strive against loneliness, depression, and anxiety [26, 30]. These observations are in line with the theory concerning the coping strategies set up by adolescents [9]. As mentioned in the Introduction, the Internet can constitute a means to escape from the "real world" and relax. It is also a space which can compensate for what the adolescents cannot obtain from the "real world". It is a different space, with different rules, allowing adolescents to find the support that they cannot find in the "real life" [3].

We have previously seen that the adolescence is a critical period where the adolescent is in his identity construction and in the need to find a group of peers. Friends to which he can identify himself with and by which he feels recognised as an individual.

Adolescents, with low self-esteem, are frequently suffering from social anxiety and possess incompletely developed communication capabilities [1]. They will meet difficulties in building solid relationships and finding a group of peers, and this will increase their feelings of loneliness. As a consequence, they will seek social ties (more) actively on the Internet.

Belfort and Miller underline how over $90 \%$ of adolescents suffering from a mental illness will seek help on the Internet [23]. Adolescents in difficulties would find it easier to seek help online or talk about them on social networks rather than asking for the help of an adult. Adolescents will seek the support of their peers, rather than the one from a professional or from an adult within their inner circle. We can hypothesise that adolescents are seeking the sharing of experiences, a diminution of their feelings of strangeness and loneliness towards their emotional storms.

The Internet is also providing a more accessible space where adolescents have the feeling of complete anonymity [23].

4.2.2. The adolescent's possibility to create social ties via the Internet

The usage of the Internet appears to be a determining element. For the adolescent, it represents the possibility of creating or strengthening social ties with peers. 
The type of platform used may have an impact. Belfort and Miller mention the risks of suicide contagion phenomenon on the Internet. However, most platforms, enabling a stronger social cohesion and a stronger support by the group of peers, seem to be less at risk of inducing suicide contagion [23]. Thus, the feeling of belonging to a group on social media could represent a protective factor.

The type of usage made by the adolescent, active or passive, can bring to different outcomes [23]. An active usage - rich in communications and interactions with peers could decrease feelings of loneliness. On the contrary, a passive usage - where one scrutinises the social network activities of their peers without interacting with them - could increase feeling of loneliness $[23,31]$. We can put this in relation with the observation that adolescent with higher level of social capabilities will easily increase their social capital, whereas adolescents lacking social capabilities will increase their feelings of loneliness [23]. It is easier to be an active user when one has a developed social network, with good social and communication skills, rather than when one is isolated and lacking those capabilities.

However, following Belfort and Miller, if the socially excluded adolescent can affiliate himself to a group of individuals representing a social minority, such as LGBTI people or those with mental illness, etc. [23], then - through the Internet - the adolescent can be provided with a social network. In fact, these kind of online communities can provide the adolescent with membership to a group, where they can share experiences and feeling supported instead of judged [32].

\subsubsection{The impact of time spent on the Internet}

Three studies make more complex every consideration on the topic. These studies highlight the possibility of increased feelings of loneliness and increased presence of suicidal thoughts for adolescents with either low or excessive usage of Internet and social media as opposed to those with a moderate usage [30-33]. Increased loneliness and suicidal ideation in adolescents characterized by low usage of Internet and social media is an important indicator of how these tools have become a necessity for our socialisation. As mentioned in the Introduction, the Internet has become a central space for gathering and exchanges amongst adolescents. Therefore, for adolescents it represents a requirement for a good social integration in a group of peers, as well as for their identity construction.

With regards to those with an excessive use of the Internet and social media, several theories have been formulated to explain the phenomenon:

- Adolescents which are narcissistically fragile, with a low self-esteem, and who possess less developed communication capabilities, are more inclined to show a stronger fear of social exclusion as well as the need of seeking social reassurance on social networks [1]. These adolescents are more at risk to develop the Fear of Missing Out [23]. Przybylski defined FoMO as "a pervasive apprehension that others might be having rewarding experiences from which one is absent" and characterized it by "the desire to stay continually connected with what others are doing" [34]. The adolescent fearing that his online absence could impact his social ties with peers, would have a tendency to remain constantly online or to obsessively check for new notifications. These obsessive behaviours are fuelled by the fear of being excluded from the group of peers, and are associated with an increase in anxiety, symptoms of depression and the feeling of loneliness.

- Wang (2018) hypothesized that adolescents with an extreme use of social media may present a phenomenon of desensitization. This phenomenon pushes them to increase their online activity, hoping for a greater gratification. However, the gratification obtained will not be as important as expected, and will generate feelings of loneliness derived from the adolescents' inability to satisfy the need for social ties online [31]. 
- Adolescents failing to satisfy their needs of social bonding, even while being online, will pursue their coping strategy by increasing their time on the Internet. By doing so, adolescents hope to satisfy, at some point, their needs or soothe their emotions.

- Wang (2018) also makes mention of Kraut's displacement hypothesis (1998), implying that the time spent online by adolescents is wasted, as they could have spent it offline with their friends, thus building stronger social ties [31, 35].

\subsection{Hypothesis for a theoretical model}

We have observed that adolescents suffering from feelings of loneliness will have higher risks of presenting an addiction to the Internet. As they are using Internet as a coping strategy, these adolescents would most often be individuals lacking self-esteem, suffering from anxiety, and with less developed communication skills.

We hypothesise that if the use of Internet allows them to create sufficiently satisfying ties with their peers, it will lead to a decrease in their feelings of loneliness, as well as the risk of having suicidal ideations. Sufficiently satisfying social ties, are ties allowing the adolescent feeling that he belongs to the group of peers. A group in which he can identify himself, in which he has trust, with whom he can share his experiences and difficulties while feeling supported and offer his support to other.

However, should the adolescent fail to find sufficiently satisfying social ties to fill his needs of social reassurance and support, including the feeling of belonging to a group of peers, he will persist in his loneliness, putting him at risk of suicide. As a coping strategy, adolescents will then increase their use of the Internet. This increase will probably be matched by a parallel decrease in time invested in non-virtual social ties, as well as by growing feelings of inability in fulfilling their needs of 'real' social ties. Feelings of social exclusion, perceived burdensomeness and self-depreciation would eventually follow. This can lead to more feelings of loneliness, boredom, and then suicide ideation.

\subsection{Limitations}

Regrettably, the literature on the interaction between feelings of loneliness, Internet addiction and suicidal ideation amongst adolescent is very limited. Our literature review provided a single result, which is in itself a literature review. In this paper, we have tried to build a theoretical model driven from dyads of those three elements. Further research is needed to verify the validity of this model. We are aware that we have possibly identified only part of the complexities that may exist in the interaction between Internet misuse, feelings of loneliness typical of adolescence and onset of suicidal ideation.

\section{Conclusions}

The Internet has become an integral part of our daily life, transforming the world of our relationships. Adolescents are the most exposed part of the population to these changes, which directly impact the entire adolescence process.

Understanding the transformations that the Internet is bringing to the lives of young individuals is of crucial importance. Adolescents' suicide prevention should pay particular attention to the impact of Internet addiction, with a view to integrate also the impact of loneliness feelings. As seen throughout this article, feelings of loneliness are one of the key elements leading to the development of suicidal ideation; they are very frequent during adolescence.

Satisfactory social ties might enable adolescents to decrease their feelings of loneliness, therefore decreasing the risk of suicidal ideation. On the contrary, should they fail to create good-quality social ties, adolescents would be confronted by feelings of social exclusion and incapability; this may lead to an increase in feelings of loneliness and eventually develop suicidal ideation.

Further research, aimed to better identify the processes in place in the interaction between feelings of loneliness, Internet addiction and suicidal ideation, could enable us to 
elaborate better suicide prevention solutions for adolescents, possibly by using their very preferred tool: the Internet.

Funding: This research received no external funding.

Informed Consent Statement: Not applicable.

Acknowledgments: /

Conflicts of Interest: The authors declare no conflict of interest.

\section{References}

1. Khatcherian, E.; Zdanowicz, N. Why do cyberbullied adolescents stay in contact with their harasser? A literature review and reflection on cyberbullied adolescents' Coping Strategies. Psychiatria Danubina 2018, 30(7), 537-540.

2. Bremer, J. The internet and children: Advantages and disadvantages. Child and Adolescent Psychiatric Clinics of North America, 2005, 14, 405-428. Doi: 10.1016/j.chc.2005.02.003

3. Achab, S. Réflexions sur les enjeux psychiques du «always-on» chez les jeunes. In Grandir à l'ère du numérique. Commission fédérale pour l'enfance et la jeunesse: Switzerland, 2019. Available online : https://www.ekkj.admin.ch/fileadmin/user_upload/ekkj/02pubblikationen/Berichte/f_2019_CFEJ_Rapport_Numerisation.pdf

4. Cheng, C.; Yee-lam Li, A. Internet addiction prevalence and quality of (real) life: A meta-analysis of 31 nations across seven world regions. Cyberpsychology, Behavior, and Social networking 2014, 17(12), 755-760. Doi: 10.1089/cyber.2014.0317

5. Chung, T. W.H.; Sum, S. M.Y.; Chan, M. W.L. Adolescent internet addiction in Hong Kong: prevalence, psychosocial correlates, and prevention. Journal of adolescent health 2019, 64(6), 34-43. Doi: https://doi.org/10.1016/j.jadohealth.2018.12.016

6. World Health Organization. Public Health implications of excessive use of the internet, computers, smartphones and similar electronic devices meeting report. 2014. https://apps.who.int/iris/bitstream/handle/10665/184264/9789241509367_eng.pdf;jsessionid $\% 20=\% 2028 C C 77 D 0 C 87966$ E0128F5AA3117641DF?sequence $\% 20=\% 201$

7. Chi, X.; Hong, X.; Chen, X. Profiles and sociodemographic correlates of internet addiction in early adolescents in southern China. Addictive behaviors 2020, 106, 106385. Doi: https://doi.org/10.1016/j.addbeh.2020.106385

8. World Health Organization. Betadraft of ICD-11. 2019; Available from: https://icd.who.int/browse11/1-m/en.

9. Achab, S.; Simon, O.; Müller, S.; Thorens, G.; Martinotti, G.; Zullino, D.; Khazaal, Y. Internet Addiction. In Textbook of Addiction Treatment: International Perspectives, 1st ed; El-Guebaly, N., Carrà, G., Galanter, M., Eds.; Springer, Milano, Italia, 2015; pp. 1499-1513. Doi 10.1007/978-88-470-5322-9_128

10. Mihajlov, M.; Vejmelka, L. Internet addiction: a review of the first twenty years. Psychiatria Danubina 2017, 29(3), 260-27. Doi: https://doi.org/10.24869/psyd.2017.260

11. Jeong, B.; Lee, J. Y.; Kim, B. M.; Park, E.; Kwon, J.-G.; Kim, D.-J.; Lee, Y.; Choi, J.-S.; Lee, D. Associations of personality and clinical characteristics with excessive internet and smartphone use in adolescents: a structural equation modelling approach. Addictive behaviors 2020, 110, 106485. Doi: https://doi.org/10.1016/j.addbeh.2020.106485

12. Dalbudak, E.; Evren, C.; Topcu, M.; Aldemir, S.; Coskun, K. S.; Bozkurt, M.; Evren, B.; Canbal, M. Relationship of internet addiction with impulsivity and severity of psychopathology among Turkish university students. Psychiatry Research 2013, 210, 1086-1091. Doi: https://dx.doi.org/10.1016/j.psychres.2013.08.014

13. Li, W.; Zhang, W.; Xiao, L.; Nie, J. The association of internet addiction symptoms with impulsiveness, loneliness, novelty seeking and behavioral inhibition system among adults with attention-deficit/hyperactivity disorder (ADHD). Psychiatry Research 2016, 243, 357-364. Doi: https://dx.doi.org/10.1016/j.psychres.2016.02.020

14. McClelland, H., Evans, J. J., Nowland, R., Ferguson, E.; O'Connor, R. C. Loneliness as a predictor of suicidal ideation and behaviour: a systematic review and meta-analysis of prospective studies. Journal of Affective Disorders 2020, 274, 880-896. Doi: https//doi.org/10.1016/j.jad.2020.05.004

15. Dupont, S. L'adolescent et l'épreuve de la solitude. Revue de l'enfance et de l'adolescence 2016, 93, 121-130.

16. Solmi, M. ; Veronese, N. ; Galvano, D. ; Favaro, A. ; G Ostinelli, E. ; Noventa, V. ; Favaretto, E. ; Tudor, F. ; Finessi, M. ; Il Shin, J. ; Smith, L. ; Koyanagi, A. ; Cester, A. ; Bolzetta, F. ; Cotroneo, A. ; Maggi, S. ; Demurtas, J. ; De Leo, D. ; Trabucchi, M. Factors associated with loneliness : an umbrella review of observational studies. Journal of Affective Disorders 2020, 271, 131-138. Doi : https://doi.org/10.1016/j.jad.2020.03.075

17. World Health Organization, Mental health and substance use team. Suicide in the world. Global health estimates. 2019. https://www.who.int/publications/i/item/suicide-in-the-world

18. Stickley, A.; Koyanagi A. Loneliness, common mental disorders and suicidal behavior: Findings from a general population survey. Journal of Affective Disorders 2016, 197, 81-87. Doi: https//dx.doi.org/10.1016/j.jad.2016.02.054

19. Joiner, T.E. Why people die by suicide. Havard University Press, Cambridge, United Kingdom, 2007.

20. Van Orden, K.A.; Witte, T.K., Cukrowicz, K.C., Selby, E. A.; Joiner, T.E. The interpersonal theory of suicide. Psychological Review 2010, 117(2), 575-600. Doi:10.1037/a0018697

21. Zadravec Šedivy, N.; Podlogar, T.; Kerr, D. C. R.; De Leo, D. Community social support as a protective factor against suicide: agender specific ecological study of 73 regions of 23 European countries. Health $\mathcal{E}$ Place 2017, 48, 40-46. Doi: https://ds.doi.org/10.1016/j.healthplace.2017.09.004 
22. Banstola, R. S. ; Ogino, T. ; Inoue, S. Self-esteem, perceived social support, social capital, and risk-behavior among urban high school adolescents in Nepal. SSM-Population Health 2020, 11, 100570. Doi : https://doi.org/10.1016/j.ssmph.2020.100570

23. Miller, A. B. ; Esposito-Smythers, C. ; Leichtweis, R. N. Rôle of social support in adolescent suicidal ideation and suicide attempts. Journal of Adolescent Health 2015, 56, 286-292. Doi : http://dx.doi.org/10.1016/j.jadohealth.2014.10.265

24. Belfort, E.L.; Miller, L. Relationship between adolescent suicidality, self-injury and media habits. Child and Adolescent Psychiatric Clinics of North America 2018, 27, 159-169. Doi: https//doi.org/10.1016/j.chc.2017.11.004

25. Primack, B.A.; Escobar-Viera, C.G. Social media as it interfaces with psychosocial development and mental illness in transitional age youth. Child and Adolescent Psychiatric Clinics of North America 2017, 26, 217-233. Doi: https//dx.doi.org/10.1016/j.chc.2016.12.007

26. Wu, X.-S.; Zhang, Z.-H.; Zhao, F.; Wang, W.-J.; Li, Y.-F.; Bi, L.; Qian, Z.-Z.; Lu, S.-S.; Feng, F.; Hu, C.-Y.; Gong F.-F.; Sun Y.-H. Prevalence of internet addiction and its association with social support and other related factors among adolescents in China. Journal of Adolescence 2016, 52, 103-111. Doi: https//dx.doi.org/10.1016/j.adolescence.2016.07.012

27. Aydin, B.; Sari, S.V. Internet addiction among adolescents: the role of self-esteem. Procedia Social and Behavioral Sciences 2011, 15, 3500-3505. Doi: 10.1016/j.sbspro.2011.04.325

28. Shi, X.; Wang, J.; Zou, H. Family functioning and internet addiction among Chinese adolescents: the mediating roles of selfesteem and loneliness. Computers in Human Behavior 2017, 76, 201-210. Doi : http://dx.doi.org/10.1016/j.chb.2017.07.028

29. Creemers, D. H.M.; Scholte, R. H.J.; Engels, R. C.M.E.; Prinstein, M. J.; Wiers R. W. Implicit and explicit self-esteem as concurrent predictors of suicidal ideation, depressive symptoms and loneliness. Journal of Behavior Therapy and Experimental Psychiatry 2012, 43, 638-646. Doi: 10.1016/j.jbtep.2011.09.006

30. Lee, S.Y.; Park, E.-C.; Han, K.-T.; Kim, S.J.; Chun, S.-Y.; Park, S. The association of level of internet use with suicidal ideation and suicide attempts in south Korean adolescents: A focus on family structure and household economic status. The Canadian Journal of Psychiatry 2016, 61(4), 243-251. Doi: 10.1177/0706743716635550

31. Wang, K.; Frison, E.; Eggermont, S.; Vandenbosch, L. Active public Facebook use and adolescents' felling of loneliness: Evidence for a curvilinear relationship. Journal of adolescence 2018, 67, 35-44. Doi: https//doi.org/10.1016/j.adolescence.2018.05.008

32. Poštuvan, V.; Podlogar, T.; Zadravec Šedivy, N.; De Leo, D. Suicide behaviour among sexual-minority youth: a review of the role of acceptance and support. Lancet Child Adolescent Health 2019, 3, 190-198. Doi: http//dx.doi.org/10.1016/s23524642(18)30400-0

33. Do, Y.K.; Shin, E.; Bautista, M.A.; Foo, K. The associations between self-reported sleep duration and adolescent health outcomes: What is the role of time spent on Internet use? Sleep Medicine 2013, 14, 195-200. Doi: https//dx.doi.org/10.1016/j.sleep.2012.09.004

34. Przybylski, A.K.; Murayama, K.; DeHaan, C.R.; Gladwell, V. Motivational, emotional, and behavioral correlates of fear of missing out. Computers in Human Behavior 2013, 29(4), 1841-1848.Doi: https://doi.org/10.1016/j.chb.2013.02.014

35. Kraut, R.; Patterson, M.; Lundmark, V. ; Kiesler, S.; Mukopadhyay, T.; Sherlis, W. Internet paradox. A social technology that reduces social involvement and psychological well-being? Americain Psychologist 1998, 53(9), 1017-1031. Doi: 10.1037//0003066x.53.9.1017 